\title{
Cloning and Characterization of Limonoid Glucosyltransferase from Kinnow Mandarin (Citrus reticulata Blanco)
}

\author{
Sumedha Arora', Prashant \\ Mohanpuria**, Gurupkar \\ Singh Sidhu', Inderjit Singh \\ Yadav ${ }^{1}$ and Vandna Kumari ${ }^{2}$ \\ 'School of Agricultural Biotechnology, \\ Punjab Agricultural University, IN- \\ 141004 Ludhiana, India \\ ${ }^{2}$ Botany Department, Punjabi \\ University, IN-147002 Patiala, India
}

Received: 19 May 2017

Accepted: 30 November 2017
${ }^{*}$ Corresponding author:

Phone: +9101612401960, ext. 270;

E-mail: pmohanpuria@pau.edu

ORCID IDs: 0000-0001-7791-6269

(Arora), 0000-0001-6891-4448

(Mohanpuria), 0000-0002-7109-9592

(Sindhu), 0000-0001-9988-945X (Yadav),

0000-0002-4316-7738 (Kumari)

\begin{abstract}
SUMMARY
Kinnow mandarin (Citrus reticulata Blanco) is a popular citrus crop of northwestern India and it occupies maximum fruit area in Punjab. However, citrus juice processing industry is still suffering from delayed bitterness problem caused mainly by limonoid aglycones such as limonin. In order to study citrus limonoid metabolism, limonoid glucosyltransferase (LGT) gene, which encodes a natural debittering enzyme, was isolated from the fruit tissues of Kinnow mandarin. After confirmation and characterization, its full-length gene sequence (1533 bp) was submitted to National Centre for Biotechnology Information. Citrus reticulata limonoid glucosyltransferase ( $C r L G T)$ occupies a position on an independent branch in the largest subgroup and is phylogenetically different from those in other mandarin species like $C$. unshiu, showing its uniqueness in several features. The transcript expression of $C r L G T$, evaluated in different tissues such as young leaf, flavedo, albedo, sac covering and seed of Kinnow mandarin during early (90 days after flowering (DAF)), mid (150-210 DAF) and late (240 DAF) fruit developmental stages using semi-quantitative method, showed the highest expression in flavedo. Thus, it was concluded that the isolated LGT gene has an effect on limonoid metabolic engineering in citrus. Overexpression of this gene can reduce the delayed bitterness problem in citrus juice and enhance the accumulation of specific glucosides that have anticancer effects.
\end{abstract}

Key words: Kinnow mandarin, delayed bitterness, limonoid glucosyltransferase, anticancer properties, semi-quantitative PCR

\section{INTRODUCTION}

Kinnow mandarin (Citrus reticulata Blanco) is a commercially important citrus fruit crop of northwestern India. It is a hybrid between King and Willow leaf mandarin (C. nobilis Lour. $\times$ C. deliciosa Tenora) and belongs to Rutaceae family. China, Brazil, USA, India, Mexico and Spain are the world's leading citrus fruit producing countries and they account for two-thirds of the global production annually. India produces 10.48 million tonnes of citrus fruits and ranks fourth in production globally (1). Kinnow mandarin occupies 61.9 $\%$ of total fruit area in Punjab and thus ranks first in fruit production in India (2). Despite this, citrus industry in India has been suffering from delayed bitterness problem caused by limonoids, mainly limonin (3). Bitterness makes the juice unacceptable to consumers and thus has a significantly negative economic impact (4). Kinnow mandarin seed, peel and juice have been reported to contain 2500,80 and $20 \mathrm{mg} / \mathrm{L}$ of limonin respectively, which is well above $6 \mathrm{mg} / \mathrm{L}$ threshold level. As a result, juice producers have to discard the juice, blend it with sugar solution or remove the bitter limonoids, which otherwise degrade the quality of the juice.

Limonoids are a group of highly oxygenated triterpenes present in Citrus species and genera belonging to the family Meliaceae. Limonoids occur in two forms, as bitter aglycones and as non-bitter glucosides in fruits and seeds of Citrus spp. (5). Intensely bitter limonoids such as limonin (dilactone) are gradually produced from the non-bitter precursor, limonoate A-ring lactone (LARL) (monolactone) during juicing process, usually due to 
freezing or physical damage of the citrus fruits. This process proceeds under acidic conditions in immature fruits and is accelerated by the action of limonin D-ring lactone hydrolase (LLH), i.e. delayed bitterness (6). Although limonoid aglycones endogenously convert into tasteless limonoid glucosides, this natural debittering process is catalyzed by limonoid glucosyltransferase (LGT), but only during fruit maturation $(7,8)$. Young immature fruit tissue contains only limonoid aglycones, while the mature one contains both aglycones and glucosides. This inter-conversion of aglycones to glucosides occurs as the fruit ripens and is carried out by these two regulatory enzymes, i.e. LGT and LLH (9).

Apart from causing delayed bitterness, recently citrus limonoids have been shown to have biological activity against several types of cancers, specifically against brain (10), colon, pancreas and breast cancers (11-14). Furthermore, citrus limonoids, specifically limonoid glucosides, which are the product of glucosyltransferase enzyme, are water-soluble and have good bioavailability and non-toxic effects in animals and humans. Thus, they can easily be used as nutraceuticals and health fortifiers in many functional foods (15).

Out of two important regulatory genes in limonoid biosynthetic pathway (Fig. 1) in most of the Citrus spp., only gene encoding LGT has been isolated from navel orange (GenBank accession number EU531465), satsuma mandarin (GenBank accession number AB033758) (16,17), lime (GenBank accession number EU531463) and grapefruit (GenBank accession number EU531464) (18). In citrus limonoid biosynthetic pathway, nomilin is the initial precursor of all limonoids synthesized in phloem region of the stem. Stem nomilin formed is translocated to other tissues including leaves, fruits and roots, where nomilin or deacetylnomilin are further capable of biosynthesizing other limonoids. Since the LGT alone seems to be capable enough of natural debittering process in fruits of citrus plants, its isolation from Kinnow mandarin would be important for creating transgenic citrus free from limonoid bitterness.

The overexpression of $L G T$ in citrus can enhance the utilization of accumulated precursor (LARL) and thus reduce the formation of bitter limonin in fruit tissues upon damage. Furthermore, this would lead to higher production of limonoid glucoside molecules, which have anticancer properties $(12,13)$. Thus, keeping in mind the importance of citrus limonoids in delayed bitterness problem and human health, the present study has been designed for the first time in India to clone and characterize full length $L G T$ gene from the fruit of Kinnow mandarin.

\section{MATERIALS AND METHODS}

\section{Chemical reagents and supplies}

All reagents were purchased from Sigma-Aldrich, Merck (St. Louis, MO, USA). Restriction enzymes were obtained from New England Biolabs, Ipswich, MA, USA, while Taq DNA polymerase, SuperScript III reverse transcriptase, and T4 DNA ligase were obtained from Invitrogen (Thermo Fisher Scientific, Waltham, MA, USA). Oligonucleotides were synthesized by Integrated DNA Technologies, Inc., Skokie, IL, USA. QIAquick

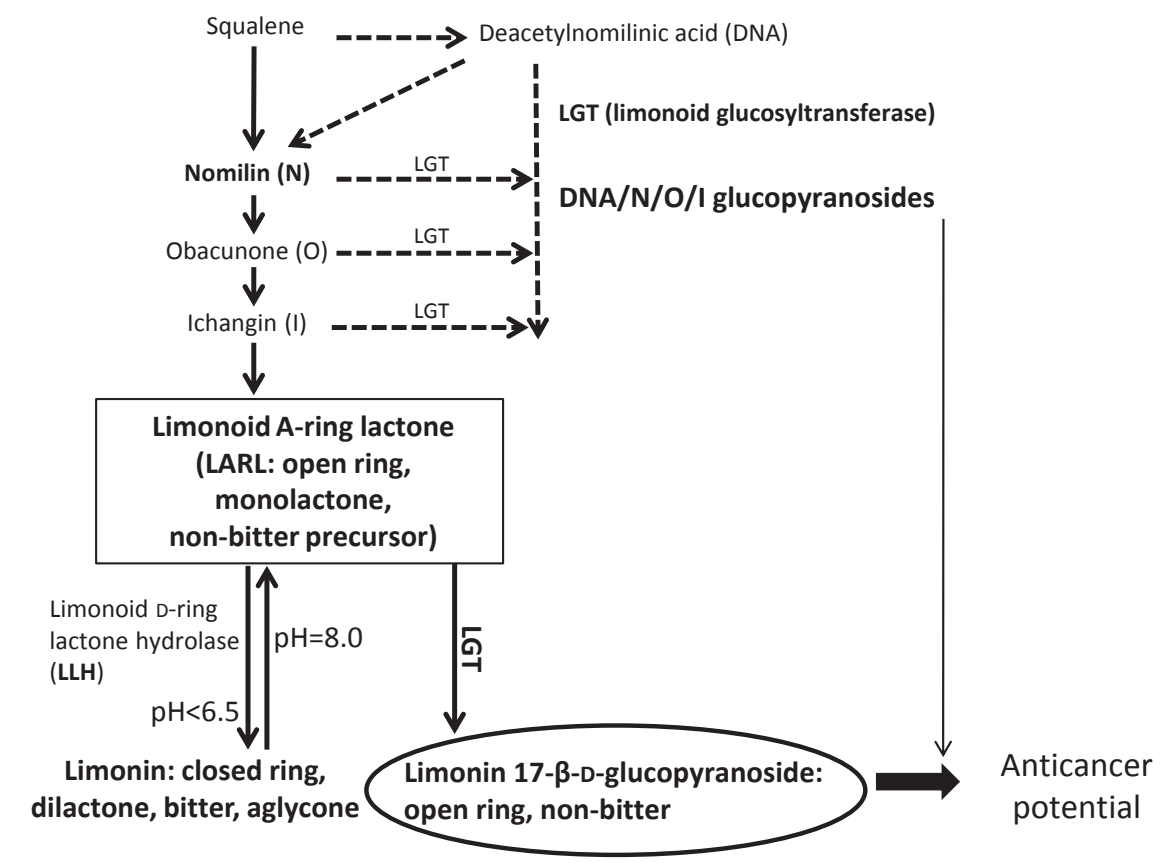

Fig. 1. The limonoid metabolism pathway in citrus plants. Limonoid glucosyltransfease (LGT) is the only single regulatory enzyme that is able to convert all limonoid aglycones such as nomilin, obacunone and ichangin present in Citrus spp. to their respective glucosides, in addition to limonoate A-ring lactone (LARL) to limonin glucopyranoside. During juicing process bitter limonin is immediately produced from LARL precursor by limonin D-ring lactone hydrolase (LLH) regulatory enzyme, especially in early to mid-stage developed citrus fruits 
gel extraction kit, DNeasy plant mini kit, RNeasy plant mini kit and QIAprep spin miniprep kits were the products of QIAGEN, Hilden, Germany.

\section{Plant materials}

Vegetative and fruit tissues of Kinnow mandarin (Citrus reticulata Blanco) were collected from Fruit Research Farm, Punjab Agricultural University, Ludhiana, India, during the seasons 2014-2016 and analyzed at School of Agricultural Biotechnology, Punjab Agricultural University, Ludhiana.

\section{Cloning and sequence analysis of Citrus reticulata limonoid} glucosyltransferase (CrLGT)

For cloning, total RNA was isolated from young leaves and fruit tissues (peel, seed and sac covering) of Kinnow mandarin using RNeasy plant mini kit as described in its manual. The quality of total RNA isolated was checked with NanoDrop (Thermo Fisher Scientific). A mass of $2 \mu \mathrm{g}$ of total RNA from each of the samples was used to prepare cDNA by using SuperScript III reverse transcriptase following the manufacturer's protocol. The 26S rRNA amplification was used as an internal control in reverse transcription-polymerase chain reaction (RT-PCR). LGT gene sequences of various Citrus spp. such as C. maxima (EU304828.1), C. unshiu (AB033758.1), C. paradisi (EU531464.1), C. limettioides (EU531463.1), C. aurantium (EU531466.1) and C. sinensis (EU531465.1) were retrieved from GenBank at NCBI (19). These gene sequences were aligned using CLUSTAL X tool (20) and conserved regions were identified. Based on the conserved regions, three $L G T$ gene-specific primer sets were designed using PerlPrimer tool (21) and DNA primers of 25 $\mathrm{nM}$ were custom synthesized. An aliquot of $2 \mu \mathrm{L}$ of the cDNA library was used as a template to carry out PCR in Thermal cycler (Applied Biosystems, Thermo Fisher Scientific). Three sets of primers were applied in different $\mathrm{PCR}$ reactions and out of these, optimal amplifications were obtained with set 3 (GT F3 5'ATGGGAACTGAATCTCTTGTTCAT 3' and GT R3 5'TCAATACTGTACACGTGTCCGTCG $3^{\prime}$ ), the amplified product was separated on $1 \%$ agarose gel in $0.5 \times$ Tris-borate-EDTA (TBE) buffer at 90 $V$ for $1 \mathrm{~h}$ and gel photograph was taken using gel documentation system (Ultra-Violet Products Ltd., Cambridge, UK). Desired PCR band was cut, purified from agarose gel and ligated into pGEM-T Easy vector (Promega Corporation, Madison, WI, USA) in 3:1 ratio. This ligated product was transformed into Escherichia coli (DH5a). The produced bacterial colonies were selected on Luria-Bertani (LB) plate containing ampicillin. These colonies were screened through PCR using the above-mentioned primers. The recombinant PGEM-T Easy plasmid was isolated from positive colonies (colonies 2-6) and was used for sequencing of the insert. The sequences of these inserts were confirmed through BLASTn (22) analysis. Further, CrLGT final nucleotide sequence was characterized by ExPASy tool (23). The predicted CrLGT protein sequence was also searched in Pfam database (24). To identify the probable cellular localization of CrLGT protein in plant cells, SignalP-4.1 server (25) was used.
PCR-restriction fragment length polymorphism of limonoid glucosyltransferase gene

To analyze Citrus reticulata limonoid glucosyltransferase (CrLGT) gene structure, firstly, we isolated genomic DNA from young leaves of three ancestral Citrus spp. such as citron, pummelo and Kinnow mandarin. PCR amplifications of CrLGT using genomic DNA isolated from Citrus spp. and cDNA prepared from RNA isolated from Kinnow mandarin were carried out using GT F3 and GT R3 primer set. After 35 cycles of PCR, the PCR products were separated on $1 \%$ agarose gel. Secondly, after getting the gene sequence, a restriction map of CrLGT gene was constructed using NEBcutter V2.0 (26) and PCR-restriction fragment length polymorphism (PCR-RFLP) pattern was generated by using $B g / l l$ restriction enzyme. For this, Bg/ll was used for restriction digestion of purified LGT from the Citrus spp. A volume of $25 \mu \mathrm{L}$ of digestion reaction contained $21.5 \mu \mathrm{L}$ of purified LGT, $2.5 \mu \mathrm{L}$ of $10 \times$ NEBuffer 3.1 and $1 \mu \mathrm{L}$ of $\mathrm{Bg} / \mathrm{ll}(10 \mathrm{U} / \mu \mathrm{L})$ enzyme. After overnight digestion at $37^{\circ} \mathrm{C}$, the digested products were resolved on $1.2 \%$ agarose gel and the photograph was taken using gel documentation system (Ultra-Violet Products Ltd.) to visualize gene fragment size.

\section{Semiquantitative PCR for CrLGT transcript expression}

In order to investigate the correlation of transcript expression of $L G T$ in vegetative and fruit tissues of Kinnow mandarin with delayed bitterness problem in its juice, the present experiment was conducted. Total RNA was isolated from vegetative and fruit tissues of Kinnow mandarin at different fruit developmental stages, i.e. early (July, 90 days after flowering (DAF)), mid (September to November, 150-210 DAF) and late (December, $240 \mathrm{DAF}$ ). The cDNA was prepared using $2 \mu \mathrm{g}$ of total RNA. An equal quantity of CDNA from each of the samples was used for RT-PCR analysis. RT-PCR was carried out using CrLGT gene specific primer set (GT F3 and GT R3) as described earlier. Optimal amplification of CrLGT transcript was standardized at exponential phase in PCR. The PCR-amplified product was separated on $1 \%$ agarose gel. The relative level of $L G T$ transcript expression was estimated densitometrically using gel documentation system (Ultra-Violet Products Ltd.).

\section{RESULTS AND DISCUSSION}

\section{Molecular cloning of CrLGT from Kinnow mandarin and its sequence comparison}

The quality and quantity of total RNA isolated from young leaves and fruit tissues (peel and seed) of Kinnow mandarin were checked on $1 \%$ denaturing agarose gel. On agarose gel, presence of intact $28 \mathrm{~S}$ and $18 \mathrm{~S}$ rRNA bands validated the good quality of isolated RNA (Fig. 2a lower panel).

The cDNA prepared using RNA from young leaves and peel was used for PCR amplification with 26S rRNA gene-specific primers (as an internal control). Using cDNA library as a template, PCR was carried out with the full-length gene-specific primers. Among three sets of primers, there was no PCR 
amplification observed with the primer pair GT F1 and GT R1, but PCR amplifications were observed with primer set 2 (GT F2 and GT R2) (figure not shown) and set 3 (GT F3 and GT R3) (Fig. 2a-Fig. 2c). The PCR products resulted in approx. 1.6-kb band using a primer set 3, while multiple bands were observed with primer set 2 . Therefore, the desired purified PCR product was cloned into PGEM-T Easy vector, which was then transformed into $E$. coli $(\mathrm{DH} 5 \mathrm{a})$. The five positive colonies (containing insert) were screened through colony PCR (Fig. $2 b)$. DNA sequencing of the insert produced a full length sequence of $C r L G T$ of 1533 bp with an open reading frame (ORF) encoding a protein of 211 amino acids with a molecular mass of approx. $28 \mathrm{kDa}$, which was shorter than the earlier reported Citrus LGT (Fig. 3).

Earlier, genes encoding LGT of sizes $1.7 \mathrm{~kb}$ from satsuma mandarin (C. unshiu; AB033758.1), $1.5 \mathrm{~kb}$ each from navel orange (C. sinensis; EU531465.1) (16,17), lime (C. limettioides; EU531463.1) and grapefruit (C. paradisi; EU531464.1) (18) were reported. The present $L G T$ gene sequence is approx. $200 \mathrm{bp}$ shorter than the earlier reported in mandarin and thus, this is a unique LGT gene sequence from Citrus reticulata reported for the first time in India. Fortunately and interestingly, this gene sequence contains start and stop codons. We compared this gene sequence with other reported LGT sequences (GenBank accession numbers: EU531463.1, EU531466.1, AB033758.1, EU531465.1, EU304828.1, EU531464.1, EU531467.1 and EF119744.1). CLUSTAL X multiple sequence alignment of CrLGT sequence with these sequences showed a high level of sequence conservation. We have noted 9 indels in this sequence [single nuceotide addition (positions 28 and 1479) and deletions (positions 49-50, 267-268, 959-960, 1004-1005 and 1501-1502), two nuceotide additions (position 14891492) and deletions (positions 1508-1509)] (Fig. 4). When the
CrLGT protein sequence was compared with that of LGT from satsuma mandarin, 139 amino acids from start and $161 \mathrm{ami}-$ no acids from end were missing, but interestingly, the plant secondary product glucosyltransferase (PSPG) box was intact, showing functionality of desired protein. Most of the plant GTase are reported to have molecular mass in the range of 40 to $58 \mathrm{kDa}$ (7), in contrast to $28-\mathrm{kDa}$ translated protein of $\mathrm{CrLGT}$ sequence. These insertions and deletions could have resulted in shorter protein in the present case.

Based on BLASTn (22) analysis, the isolated gene showed $98 \%$ sequence identity with the limonoid uridine diphosphate (UDP)-glucosyltransferase gene from Citrus sinensis (EU531465.1), C. paradisi (EU531464.1), C. limettioides (EU531463.1) and C. unshiu (AB033758.1). Phylogenetic diagram of nucleotide sequences of different citrus limonoid glucosyltransferases showing three groups was prepared, where the lowest branch is covering most of the sequences including LGT sequence from Kinnow mandarin (Fig. 5). The CrLGT occupies independent branch position in the largest subgroup and is phylogenetically different from that of other mandarins such as $C$. unshiu and thus, showing its uniqueness.

The CrLGT sequence analysis by ExPASy tool (23) revealed the longest ORF of 636 bp codes for 211 amino acids (Fig. $3)$. In order to identify conserved domain in this protein sequence, BLAST conserved domain database (27) search was used, which confirmed that it belongs to the superfamily PLN03004 (UDP-glycosyltransferase). The protein sequence was also searched in Pfam database (24) to identify the family it belongs to, and it was matched with UDPGT (UDP-glucuronosyl and UDP-glucosyltransferase) family from amino acid positions 104 to 179 . The predicted amino acid sequence was used for protein search in BLAST (19) at NCBI and was found to share $99 \%$ identity with LGT of C. sinensis (ACD14145.1), 94
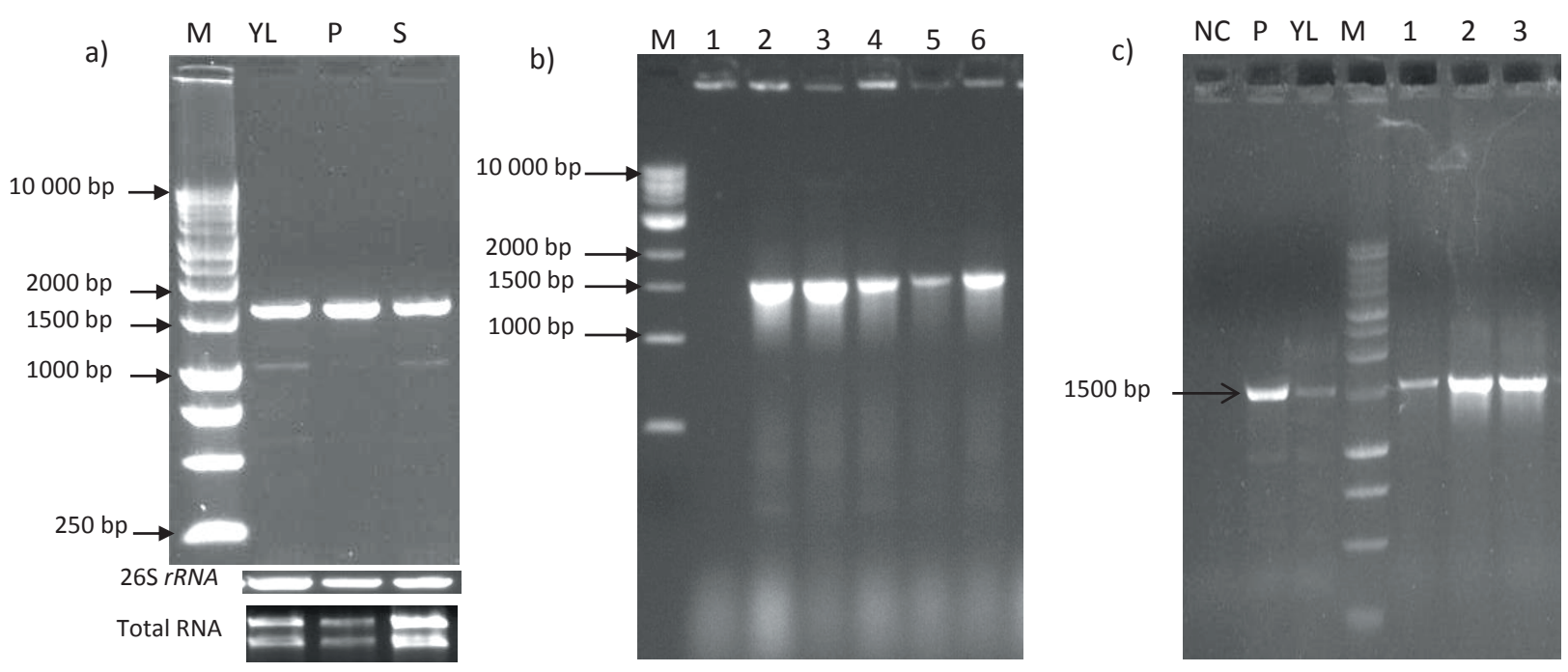

Fig. 2. Isolation of limonoid glucosyltransferase gene ( $L G T$ ) from Kinnow mandarin: a) CDNA-PCR amplification of $L G T$ from young leaves (YL), peel (P) and seed (S), b) colony PCR result showing cloning of CrLGT into pGEM-T Easy, and c) PCR amplifications of CrLGT from genomic DNA of citron (1), pummelo (2) and Kinnow mandarin (3) as well as CDNA from peel and young leaves of Kinnow mandarin, where M=1000 bp DNA ladder loaded and $\mathrm{NC}=$ negative control ( $\mathrm{PCR}$ product with no template) was loaded 


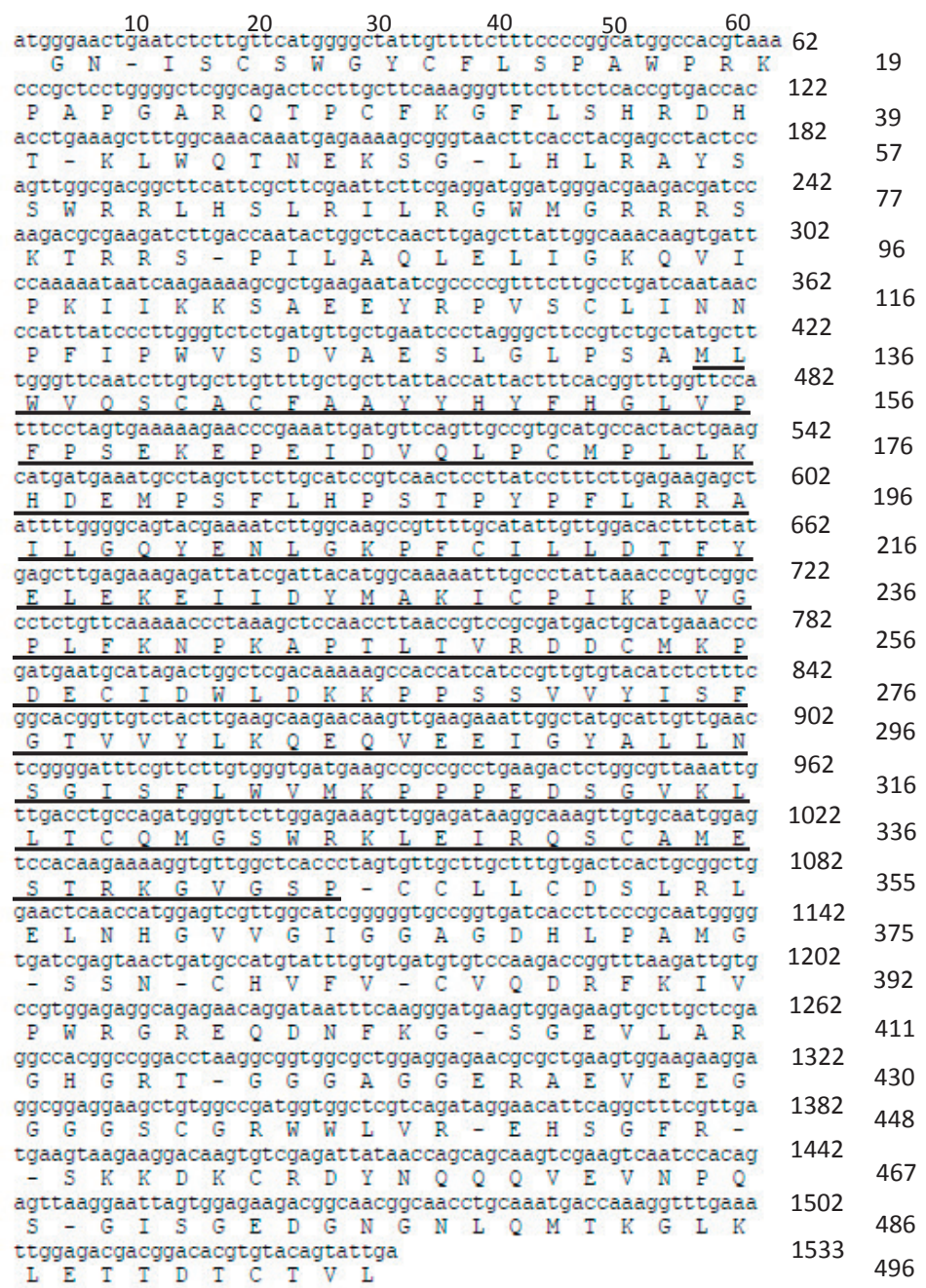

Fig. 3. The nucleotide sequence of the cDNA encoding limonoid glucosyltransferase (LGT) from Kinnow mandarin (GenBank accession number KP306791) and the deduced amino acid sequences. Underlined sequence is the deduced 211 amino acid sequence using the functional open reading frame (ORF) of LGT. Nucleotides are numbered above as well as on the right side of the sequence, and the deduced amino acid residues at the far right

$\%$ identity with LGT of C. paradisi (ACD14144.1), $97 \%$ identity with LGT of C. maxima (ABY27084.1) and $99 \%$ with that of $C$. unshiu (ABX46237.1). In order to identify the cellular location of CrLGT protein, we used the SignalP-4.1 (25) server to predict the presence of any signal peptide. No signal peptide region was predicted for its translated sequence, which suggests that the protein is probably expressed or accumulated in the cytoplasm. After several comparisons and confirmation of this full-length LGT gene sequence, it was submitted to NCBI (GenBank accession number KP306791).

\section{Structure of CrLGT genomic and CDNA sequence}

In order to confirm the presence/absence of any intron in the CrLGT gene, we compared the sequences of CrLGT from genomic DNA and CDNA amplifications in PCR, which resulted in an equally sized band of $1.5 \mathrm{~kb}$ with the same nucleotide sequence and this revealed the intronless $L G T$ gene isolated in this work (Fig. 2c). In a similar manner earlier, LGT from navel orange was also reported to have no introns at all (17). These facts are true as several glucosyltransferases have been reported from plants with no intron or fewer number of introns such as zeatin O-glucosyltransferase from Phaseolus lunatus (28). In addition, members of glycosyltransferase to which glucosyltransferases belong also lack or possess very low number of introns such as glycosyltransferase reported from Arabidopsis thaliana (29).

In order to study any nucleotide sequence variation in LGT from three ancestral Citrus spp. such as Kinnow mandarin, pummelo and citron (30), Bglll restriction site was chosen for generating its RFLP pattern. However, no sequence variation was observed based on the restricted fragments (data not shown). This indicates that Kinnow mandarin may contain the homozygous loci for the isolated LGT. Earlier, Kita et al. (16) reported two alleles, CitLGT-1 and CitLGT-2, in satsuma mandarin (C. unshiu), while the navel orange (C. sinensis) was demonstrated to be homozygous for CitLGT-1. PCR-RFLP pattern from the progeny of 

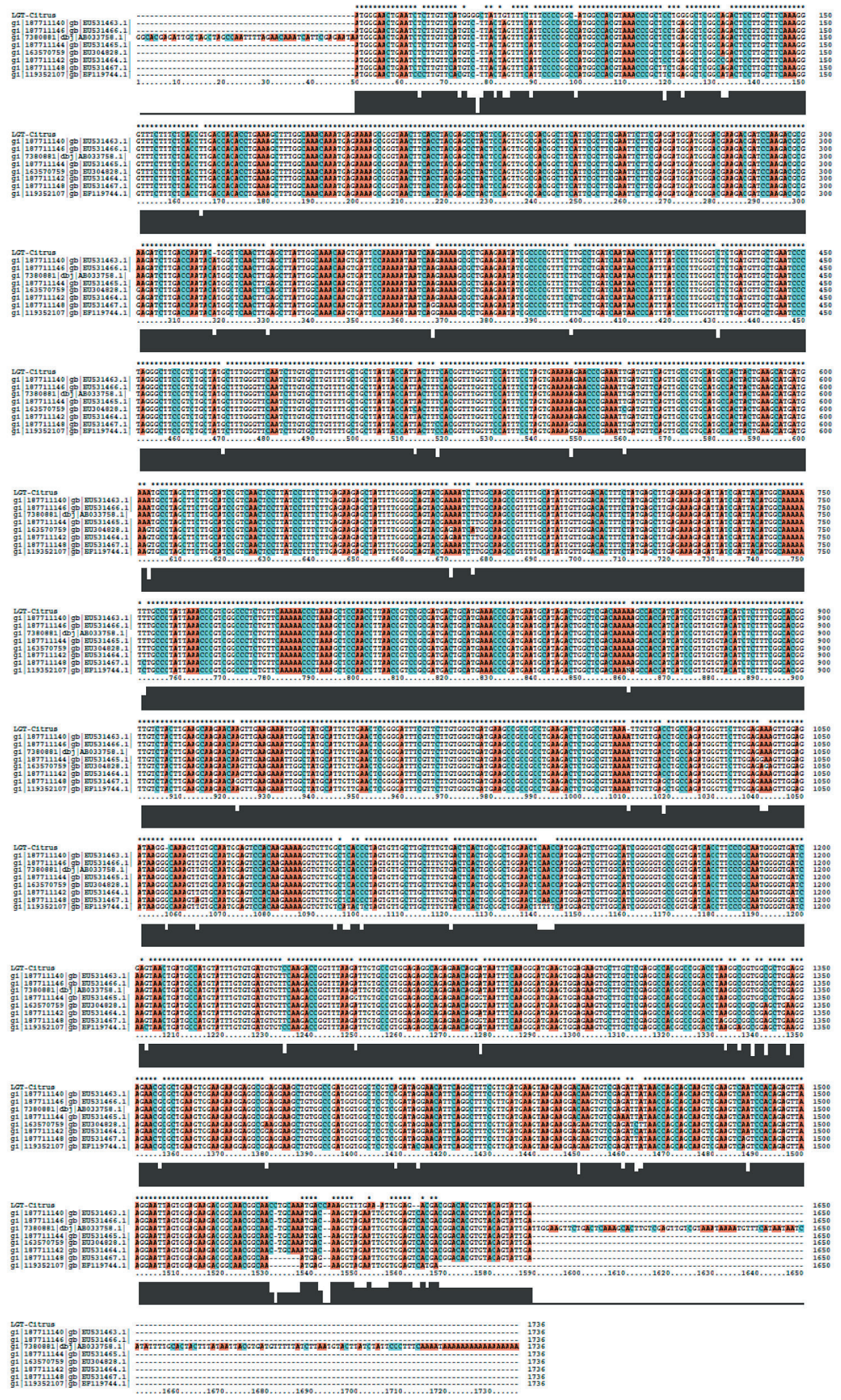

Fig. 4. Comparison of Citrus reticulata limonoid glucosyltransfease (CrLGT) from Kinnow mandarin with other cDNA sequences of glucosyltransferases. CLUSTAL X (20) multiple sequence alignment of CrLGT sequence with other sequences shows a high level of sequence conservation 


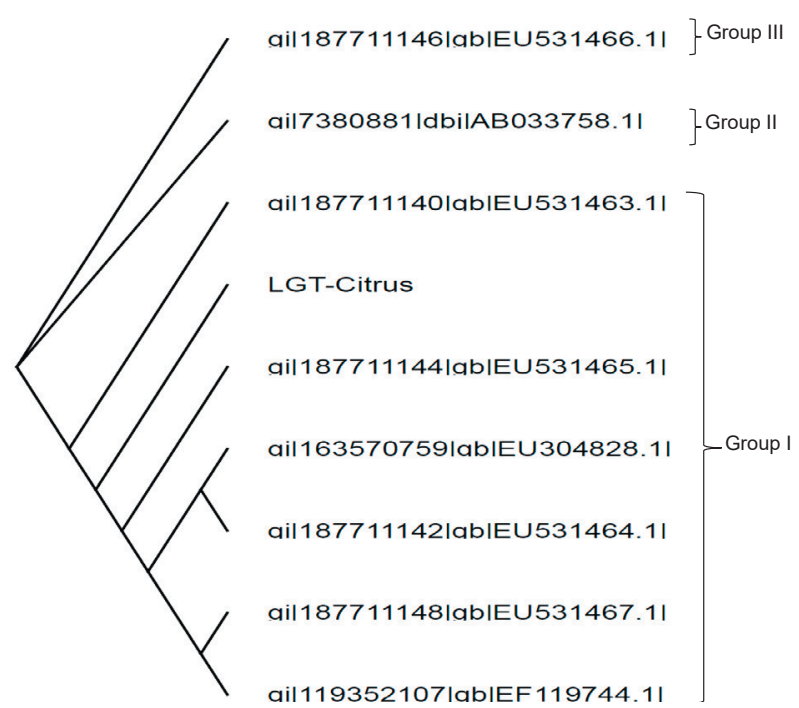

Fig. 5. Phylogenetic diagram of nucleotide sequences of different citrus limonoid glucosyltransferases (LGTs). The isolated CrLGT (GenBank accession number KP306791) is occupying independent branch position in the largest subgroup
Miyagawa wase (a cultivar of Satsuma mandarin) and Kiyomi tangor (a hybrid between Miyagawa wase and Trovita orange) revealed three allelic structures (CitLGT-1/CitLGT-1, CitLGT-1/CitLGT-2, and CitLGT-2/CitLGT-2).

\section{Limonoid glucosyltransferase expression in vegetative and fruit tissues of Kinnow mandarin}

The transcript expression of CrLGT was evaluated in different tissues such as young leaf, peel (including flavedo and albedo), sac covering and seed of Kinnow mandarin (Fig. 6a-Fig. 6d) during early (July, 90 DAF), mid (September to November, 150-210 DAF) and late (December, 240 DAF) fruit developmental stages using semi-quantitative method.

Distinctive juice delayed bitterness problem in mandarins like satsuma has not been reported (18). However, based on our practical taste-based experiment with Kinnow mandarin juice, the delayed bitterness problem occurred during early to mid-fruit developmental stages (Table 1). Harvesting of Kinnow mandarin fruits in Punjab (India) starts in October and thus its juice will certainly have delayed bitterness problem.

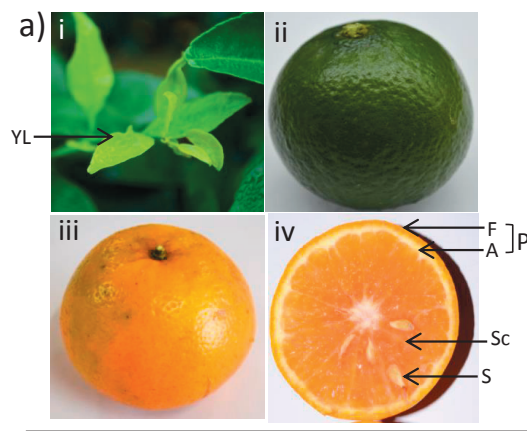

b)

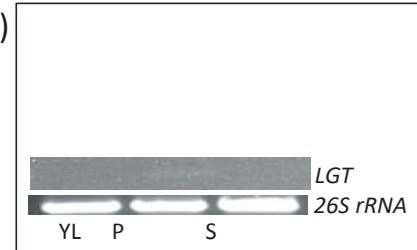

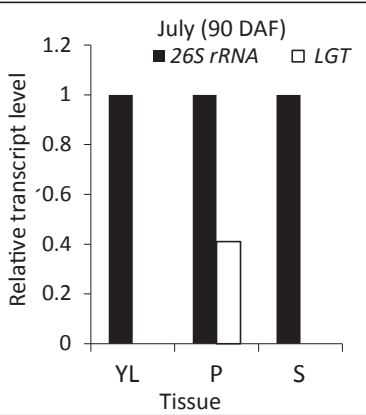
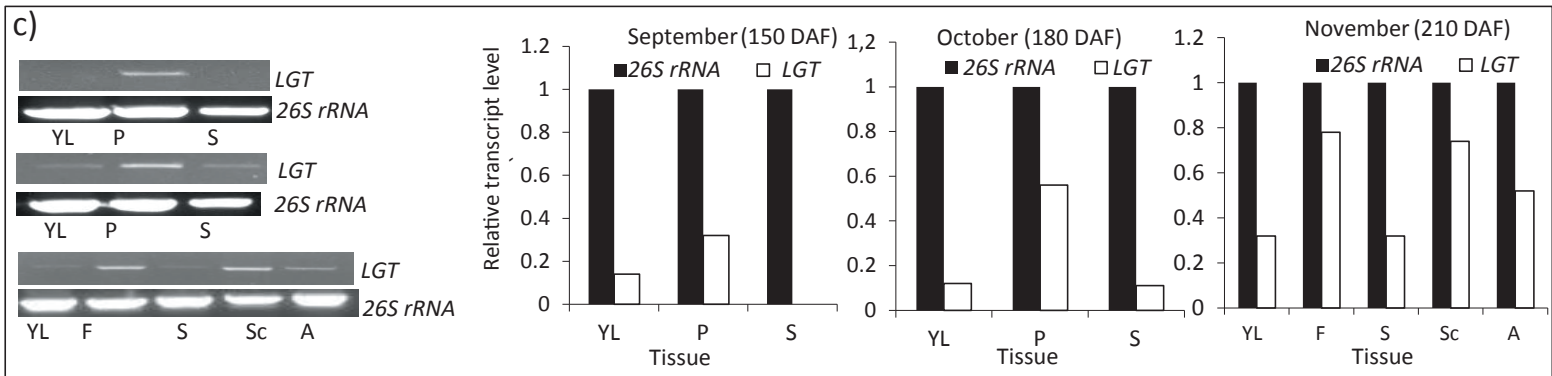

d)
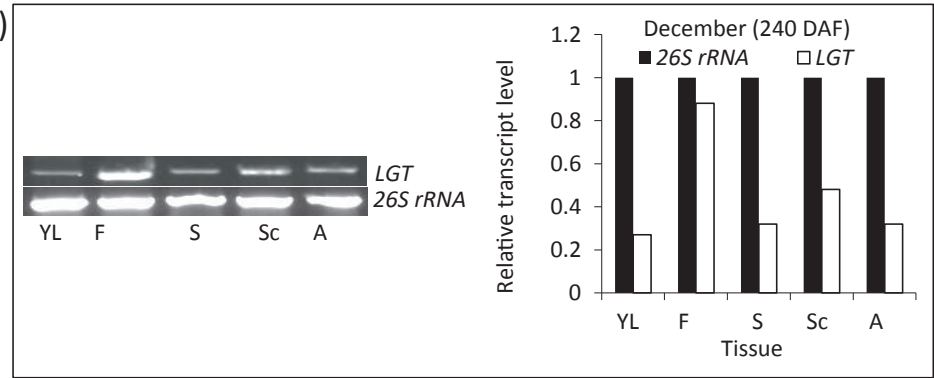

Fig. 6. Limonoid glucosyltransferase (LGT) transcript expression in vegetative and fruit tissues of Kinnow mandarin: a) young leaf (YL) and immature, and mature fruit parts ( $\mathrm{F}=$ flavedo, $\mathrm{A}=$ albedo, $\mathrm{P}=$ peel, $\mathrm{Sc}=$ sac covering and $\mathrm{S}=$ seed), $\mathrm{b}-\mathrm{d}$ ) expression levels of $L G T$ in different tissues during early ( 90 days after flowering (DAF), July), mid (150-210 DAF, September to November) and late (240 DAF, December) fruit developmental stages. The lower panel in gel pictures shows expression of $26 \mathrm{~S} r R N A$ as an internal control. Bar diagram represents relative levels of transcript expression 
Table 1. Bitterness observed (tasted) in fruits of Kinnow mandarin at early, mid and late fruit developmental stages after $4 \mathrm{~h}$ of juice extraction at room temperature

\begin{tabular}{lcc}
$\begin{array}{l}\text { Fruit developmental } \\
\text { stage }\end{array}$ & $\begin{array}{l}\text { Bitterness of juice } \\
\text { extracted with seeds }\end{array}$ & $\begin{array}{l}\text { Bitterness of juice } \\
\text { extracted without } \\
\text { seeds }\end{array}$ \\
July-August (early) & 1 & 1 \\
September (mid) & 2 & 2 \\
October (mid) & 2 & 2.5 \\
November (mid) & 3 & 3.5 \\
December (late) & 4 & 4 \\
\hline
\end{tabular}

Sensory evaluation scale of bitterness: $1=$ extremely bitter, $2=$ very bitter, $3=$ bitter, $4=$ moderately bitter (sweet), $5=$ slightly bitter (sweeter)

From July to October three types of tissues, i.e. young leaf, peel and seed were used for expression analysis of CrLGT, while from November to December, five tissues: young leaf, flavedo, albedo, sac covering and seed were used. Transcript expression of CrLGT was started 90 DAF only in peel tissue of Kinnow mandarin (Fig. 6b) in comparison to that of 60 DAF in fruit tissues (albedo) of satsuma mandarin (18), which is reported to have no distinctive juice delayed bitterness problem. A higher, as well as early expression of $L G T$, was observed in peel (including flavedo and albedo) than in all other tissues in three fruit developmental stages. However, the delayed bitterness was still present in Kinnow mandarin juice (Table 1). This shows that late expression of LGT in fruit tissues could be the cause of delayed bitterness production in citrus juices. Other than in the case of mandarin, in sweet lime and grapefruit, LGT started very late (210 DAF) in leaves and fruits and that could be the reason why these Citrus spp. have intense juice delayed bitterness (18). In another study of grapefruit (31), PGT 8 (putative glucosyltransferase) expression was found only in fruit tissues, particularly in segment membrane only after extended PCR cycles, while it was not quantifiable in vegetative tissues. In support of weak delayed bitterness during late citrus fruit developmental stage, it has been reported that the site of metabolization of limonoid aglycones to glucosides by LGT is limited only to the seed and mature fruits of citrus $(32,33)$. A similar LGT expression in leaves (150 DAF) has been observed in satsuma mandarin, as well as in Kinnow mandarin (Fig. 6c). As CrLGT expression in young leaf was constantly observed even up to the end of late fruit developmental stage, the delayed bitterness problem still existed in the fruit juice. This means that the expression pattern of $C r L G T$ in leaves is not related to the bitterness level of fruit juice, as observed earlier (18). Furthermore, there are not any reports of transport of limonoid glucosides from leaf to fruit, and once synthesized in the leaf, they cannot be translocated to another part $(32,33)$.

In contrast to mandarin, LGT transcript expression in C. aurantium and $C$. sinensis starts from 120 DAF in albedo tissue, while in the leaves, it starts expressing after 180 DAF. In C. Iimettoides and C. paradisi (which are very sour in nature), LGT expression starts very late (180 DAF) in leaves and 210 DAF in albedo. During mid-fruit developmental stage of Kinnow mandarin, flavedo showed a higher relative transcript level of CrLGT, followed by sac covering and albedo, and it was higher than in young leaf and seed, where the expression pattern was somewhat similar after 180 and 210 DAF (Fig. 6c). Interestingly, this gene started to express in seed of Kinnow mandarin during the mid-stage but at a slow pace, which has not reported so far.

In the late stage of fruit development, $C r L G T$ expression was maximum in flavedo and sac covering (Fig. 6d), as reported earlier in navel orange where CitLGT transcribed strongly in sac covering and albedo (17). Furthermore, an increase of CitLGT transcript level is parallel to the fruit maturation and thus conversion of LARL to limonoid glucoside and CitLGT mRNA accumulation could probably take place simultaneously with limonoid glucoside production. This suggests that CitLGT gene has certainly a regulatory role in limonoid glucoside accumulation and reduction of the bitterness in fruit tissues of citrus, especially in navel orange (34). In contrast to these studies, i.e. despite the high transcription of CitLGT mRNA in flower and fruit of navel orange at early stage (40 DAF), limonoid glucosides were not detected probably because of high glucosidase activity (35). In lemon, limonoid glucoside biosynthesis in fruit tissues and seeds was reported, but not in stems and leaves (36). Thus, it was noted that the expression was highest in peel, particularly in flavedo portion. Earlier, LGT expression was observed by RT-PCR analysis or Northern blot analysis in different Citrus spp. (16). Despite the expression of CrLGT during all fruit developmental stages of Kinnow mandarin, the delayed bitterness was observed. There is a possibility that post-translational modifications such as glycosylation and phosphorylation of LGT may be related to its gene expression in citrus. It could be possible to avoid delayed bitterness in Kinnow mandarin juices with a controlled higher expression of CrLGT. Taking into account that a single copy of regulatory gene present in the citrus genome converts all aglycones to their respective glucosides, the addition of extra copy of LGT would be purposeful for the accumulation of limonoid glucosides, which have potential anticancer properties (37).

\section{CONCLUSIONS}

The isolation of limonoid glucosyltransferase (LGT) gene from fruit tissues of Kinnow mandarin, a popular citrus cultivar of India, was investigated. The Citrus reticulata limonoid glucosyltransferase ( $C r L G T)$ has been reported as a key player for natural debittering and anticancer potential. This CrLGT showed several indels, absence of introns and produced a shorter translated product but with intact plant secondary product glucosyltransferase box, which is important for glycosylation. It occupied an independent branch position and thus is phylogenetically different from other LGT reported from mandarin. This isolated CrLGT gene showed highest expression in peel (flavedo) among tissues. Overexpression of this gene in citrus may divert its expression from flavedo to other useful parts like sac covering or seed to overcome the 
delayed bitterness problem in juices. Therefore, this gene will have a role in metabolic engineering of citrus limonoids for the production of food and medicine in future.

\section{CONFLICT OF INTEREST}

All authors have no conflict of interest to declare for this manuscript.

\section{ACKNOWLEDGEMENTS}

The authors are thankful to the Punjab Agricultural University, Ludhiana, India, for providing the internal grant to carry out the present research work. Authors are thankful to Dr. (Mrs.) Parveen Chunneja for providing bioinformatics facility funded by Department of Biotechnology, Government of India to carry out part of this work.

\section{REFERENCES}

1. Indian Council of Agricultural Research-National Research Centre for Citrus, (ICAR-NRCC). Nagpur, India; 2015. Available from: http://www.ccringp.org.in/ccringp/PDF/2015/ CCRINagpur(Vision2050).pdf.

2. Statement showing the district wise area, av. yield and production of various fruit crops for the year 2014-15 in the Punjab state. Directorate of Horticulture Punjab, Punjab, India; 2015. Avaialble from: http://punjabhorticulture. com/wp-content/themes/twentyeleven/document/fruits/ Fruits\%202014-15.pdf.

3. Puri M, Marwaha SS, Kothari RM, Kennedy JF. Biochemical basis of bitterness in citrus fruit juices and biotech approaches for debittering. Crit Rev Biotech. 1996;16(2):145-55. https://doi.org/10.3109/07388559609147419

4. Maier VP, Bennett RD, Hasegawa S. Limonin and other limonoids. In: Nagy S, Shaw P, Velduis MK, editors. Citrus science and technology. Westport, CT, USA: Avi Publishing Co; 1977. pp. 335-96.

5. Manners GD, Breksa III AP. Identifying citrus limonoid aglycones by HPLC-EI/MS and HPLC-APCI/MS techniques. Phytochem Anal. 2004;15(6):372-81. https://doi.org/10.1002/pca.790

6. Maier VP, Hasegawa S, Hera E. Limonin D-ring lactone hydrolase. A new enzyme from citrus seeds. Phytochemistry. 1969;8(2):405-7. https://doi.org/10.1016/S0031-9422(00)85439-4

7. Hasegawa S, Suhayda CG, Hsu WJ, Robertson, GH. Purification of limonoid glucosyltransferase from navel orange albedo tissues. Phytochemistry. 1997;46(1):33-7. https://doi.org/10.1016/S0031-9422(97)00216-1

8. Endo T, Kita M, Shimada T, Moriguchi T, Hidaka T, Matsumoto $\mathrm{R}$, et al. Modification of limonoid metabolism in suspension cell culture of Citrus. Plant Biotechnol. 2002;19(5):397-403. https://doi.org/10.5511/plantbiotechnology.19.397

9. Hasegawa $\mathrm{S}$, Ou P, Fong CH, Herman Z, Coggins Jr CW, Atkin DR. Changes in the limonoate A-ring lactone and li- monin 17-beta-D-glucopyranoside content of navel oranges during fruit growth and maturation. J Agric Food Chem. 1991;39(2):262-5.

https://doi.org/10.1021/jf00002a008

10. Poulose SM, Harris ED, Patil BS. Antiproliferative effects of citrus limonoids against human neuroblastoma and colonic adenocarcinoma cells. Nutr Cancer. 2006;56(1):103-12. https://doi.org/10.1207/s15327914nc5601_14

11. Miller EG, Porter JL, Binnie WH, Guo IY, Hasegawa S. Further studies on the anticancer activity of citrus limonoids. J Agric Food Chem. 2004;52(15):4908-12.

https://doi.org/10.1021/jf049698g

12. Kim J, Jayaprakasha GK, Vikram A, Patil BS. Cancer chemopreventive properties of citrus limonoids. In: Patil BS, Jayaprakasha GK, Murthy KNC, Seeram NP, editors. Emerging trends in dietary components for preventing and combating disease. Washington, DC, USA: American Chemical Society; 2012. pp. 37-50.

13. Chidambara Murthy KN, Jayaprakasha GK, Patil BS. Citrus limonoids and curcumin additively inhibit human colon cancer cells. Food Funct. 2013;4(5):803-10. https://doi.org/10.1039/c3fo30325j

14. Tundis R, Loizzo MR, Menichini F. An overview on chemical aspects and potential health benefits of limonoids and their derivatives. Crit Rev Food Sci Nutr. 2014;54(2):225-50. https://doi.org/10.1080/10408398.2011.581400

15. Manners GD, Jacob RA, Breksa AP III, Schoch TK, Hasegawa S. Bioavailability of citrus limonoids in humans. J Agric Food Chem. 2003;51(14):4156-61. https://doi.org/10.1021/jf0300691

16. Kita M, Hirata $Y$, Moriguchi T, Endo-Inagaki T, Matsumoto $\mathrm{R}$, Hasegawa S, et al. Molecular cloning and characterization of a novel gene encoding limonoid UDP-glucosyltransferase in Citrus. FEBS Lett. 2000;469(2-3):173-8. https://doi.org/10.1021/jf0300691

17. Kita M, Endo T, Shimada T, Moriguchi T, Hirata Y, Hasegawa S, Omura M. Allelic structures of UDP-glucose: Limonoid glucosyltransferase affect limonoid bitterness in Citrus unshiu and C. sinensis. Euphytica. 2003;132:87-94. https://doi.org/10.1023/A:1024603114997

18. Zaare-Nahandi F, Hosseinkhani S, Zamani Z, Asadi-Abkenar A, Omidbaigi R. Delay expression of limonoid UDP-glucosyltransferase makes delayed bitterness in citrus. Biochem Biophys Res Commun. 2008;371(1):59-62. https://doi.org/10.1016/j.bbrc.2008.03.157

19. Benson DA, Cavanaugh M, Clark K, Karsch-Mizrachi I, Lipman DJ, Ostell J, Sayers EW. GenBank. Nucleic Acids Res. 2013;41(D1):D36-42. https://doi.org/10.1093/nar/gks1195

20. Larkin MA, Blackshields G, Brown NP, Chenna R, McGettigan PA, McWilliam H, et al. Clustal W and Clustal X version 2.0. Bioinformatics. 2007;23(21):2947-48. https://doi.org/10.1093/bioinformatics/btm404 
21. Marshall OJ. PerlPrimer: Cross-platform, graphical primer design for standard, bisulphite and real-time PCR. Bioinformatics 2004;20(15):2471-2.

https://doi.org/10.1093/bioinformatics/bth254

22. Altschul SF, Gish W, Miller W, Myers EW, Lipman DJ. Basic local alignment search tool. J Mol Biol. 1990;215(3):403-10. https://doi.org/10.1016/S0022-2836(05)80360-2

23. Gasteiger E, Gattiker A, Hoogland C, Ivanyi I, Appel RD, Bairoch A. ExPASy: The proteomics server for in-depth protein knowledge and analysis. Nucleic Acids Res. 2003;31(13):3784-8. https://doi.org/10.1093/nar/gkg563

24. Finn RD, Coggill P, Eberhardt RY, Eddy SR, Mistry J, Mitchell AL, et al. The PFam protein families database: Towards a more sustainable future. Nuceic Acids Res. 2016;44(D1):D279-85. https://doi.org/10.1093/nar/gkv1344

25. Nielsen $H$. Protein function prediction. In: Kihara $D$, editor. Methods in molecular biology, vol. 1611. New York, NY, USA: Springer Science+Business Media LLC; 2017. pp. 59-73. https://doi.org/10.1007/978-1-4939-7015-5

26. Vincze T, Posfai J, Roberts RJ. NEBcutter: A program to cleave DNA with restriction enzymes. Nucleic Acids Res. 2003;31(13):3688-91. https://doi.org/10.1093/nar/gkg526

27. Marchler-Bauer A, Zheng C, Chitsaz F, Derbyshire MK, Geer LY, Geer RC, et al. CDD: Conserved domains and protein three-dimensional structure. Nucleic Acids Res. 2012; 41(D1):D348-52. http://doi.org/10.1093/nar/gks1243

28. Martin RC, Mok MC, Mok DWS. A gene encoding the cytokinin enzyme zeatin O-xylosyltransferase of Phaseolus vulgaris. Plant Physiol. 1999;120(2):553-8. https://doi.org/10.1104/pp.120.2.553

29. Ross J, Li Y, Lim E, Bowles DJ. Higher plant glycosyltransferases. Genome Biol. 2001;2(2):reviews3004.
30. Swingle WT. The botany of citrus and its wild relatives. In: Reuther W, Webber HJ, Batchelor LD, editors. The citrus industry. Berkeley, CA, USA: University of California Press; 1967. pp. 389-90.

31. Daniel JJ, Owens DK, McIntosh CA. Secondary product glucosyltransferase and putative glucosyltransferase expression during Citrus paradisi (c.v. Duncan) growth and development. Phytochemistry. 2011;72(14-15):1732-8.

https://doi.org/10.1016/j.phytochem.2011.04.024

32. Herman Z, Fong $\mathrm{CH}$, Hasegawa S. Biosynthesis of limonoid glucosides in navel orange. Phytochemistry. 1991;30(5):1487-8. https://doi.org/10.1016/0031-9422(91)84193-V

33. Fong $\mathrm{CH}$, Hasegawa S, Coggins Jr CW, Atkin DR, Miyake M. Contents of limonoids and limonin 17- $\beta$-D-glucopyranoside in fruit tissue of Valencia orange during fruit growth and maturation. J Agric Food Chem. 1992;40(7):1178-81. https://doi.org/10.1021/jf00019a019

34. Moriguchi T, Kita M, Hasegawa S, Omura M. Molecular approach to citrus flavonoid and limonoid biosynthesis. J Food Agric Environ. 2003;1:22-5.

35. Hasegawa S, Miyake M. Biochemistry and biological functions of citrus limonoids. Food Rev Int. 1996;12(4):413-35. https://doi.org/10.1080/87559129609541089

36. Fong $\mathrm{CH}$, Hasegawa S, Herman Z, Ou P. Biosynthesis of limonoid glucosides in lemon (Citrus limon). J Sci Food Agric. 1991;54(3):393-8. https://doi.org/10.1002/jsfa.2740540310

37. Arora S, Patel E, Sharma P, Sidhu GS, Mohanpuria P. Citrus limonoids: extraction, and metabolic engineering for human health. Book of abstracts of the 19th Punjab Science Congress on Influence of Science and Technology on Environment and Human Health; 2016 February 7-9, Mohali, Punjab, India. p. B-P03. 